\title{
A Configuração das Lógicas Institucionais do Campo da Cachaça de Alambique em Minas Gerais ${ }^{1}$
}

\author{
André Luiz de Paiva ${ }^{2}$ e Mozar José de Brito ${ }^{3}$
}

\begin{abstract}
Resumo: O campo organizacional da cachaça de alambique em Minas Gerais é constituído por diferentes atores e estruturas sociais. Esta configuração passou por diversas transformações desde o período colonial, marcado pela fabricação e pelo consumo marginalizados, até a atualidade, quando a bebida se consolidou como símbolo da cultura nacional. Em certos segmentos, a cachaça figura, inclusive, como um produto de alta distinção social e ampla inserção no mercado externo. Nessa direção, este trabalho teve como objetivo descrever a configuração das lógicas institucionais que constituem esse campo organizacional. Inicialmente, procuramos resgatar o contexto sócio histórico da bebida por meio de fontes documentais e entrevistas com atores que representam organizações do campo. Em seguida, delineamos as quatro principais lógicas que servem de referência para os produtores de cachaça de alambique, a saber: tradição, mercado, Estado e a lógica técnico-científica. Descrevemos os principais aspectos constitutivos destas lógicas, destacando seus pressupostos e orientações em relação a práticas e à dimensão simbólica. Nessa direção, foi possível evidenciar como a dinâmica institucional, especialmente a partir da emergência da lógica técnico-científica, orientou mudanças na configuração normativa da produção e do consumo de cachaça.
\end{abstract}

Palavras-chaves: Cachaça de alambique, lógicas institucionais, pluralismo institucional.

Abstract: The organizational field of alembic cachaça in Minas Gerais is composed by different actors and social structures. This configuration underwent several transformations from the colonial period, marked by marginalized manufacturing and consumption, until nowadays, when the beverage has been consolidated as a symbol of the national culture. In certain segments, cachaça is included as a product of high social distinction and wide insertion in the international market. In this direction, this work aimed to describe the configuration of the institutional logics that constitute this organizational field. Initially, we sought to recover the socio-historical context of the drink through documentary sources and interviews with actors representing the organizations of the field. Next, we outlined four main logics that serve as reference for producers of alembic cachaça, namely:

1. Data de submissão: 21 de maio de 2017. Data de aceite: 26 de fevereiro de 2018.

2. Universidade Federal de Lavras. Lavras, Minas Gerais, Brasil. E-mail: andrepaiva2@gmail.com

3. Universidade Federal de Lavras. Lavras, Minas Gerais, Brasil. E-mail: mozarbrito@gmail.com 
tradition, market, state and a technical-scientific logic. We described the main constituent elements of these logics, highlighting their assumptions and orientations in relation to symbolic and practice dimensions. Thus, it was possible to show how the institutional dynamics, especially from the emergence of technical-scientific logic, guided changes in the normative configuration of cachaça production and consumption.

Key-words: Alembic cachaça, institutional logics, institutional pluralism.

Classificação JEL: M00.

DOI: http://dx.doi.org/10.1590/1234-56781806-94790560409

\section{Introdução}

A cachaça é considerada uma bebida genuinamente brasileira. Produzida de modo artesanal ou industrial, por meio de processos fermentativos do mosto da cana-de-açúcar e então destilada, esta bebida é consumida em todo o território nacional (COUTINHO, 2001). A partir da fabricação artesanal extrai-se a também denominada 'cachaça de alambique'. No que se refere à essa variante observa-se que a cadeia produtiva da bebida passou por diversas transformações ao longo dos seus quase cinco séculos de existência. Durante o período colonial, a cachaça era marcada pela fabricação e consumo marginalizados. No entanto, atualmente, o destilado é reconhecido como símbolo da cultura nacional, figurando, em alguns casos, como um produto de alto valor econômico e inserção internacional (OLIVEIRA et al., 2012; SOUZA e CUNHA, 2012; SILVA, 2015).

Essas transformações foram de grande importância para a reconstrução das dimensões simbólica e material relacionada à produção artesanal da cachaça. Contudo, algumas características, tais como o alto índice de informalidade, ainda perduram amplamente nesse campo (BRAGA e KYIOTANI, 2015). De todo modo, Lima (2013, p. 71) argumenta que a cachaça de alambique "passa por um momento de transição entre a tradição e a renovação".

Minas Gerais se destaca como o maior produtor de cachaça de alambique do País, sendo responsável por $50 \%$ da fabricação total dessa variante da bebida. Além disso, estima-se que existam 9.000 unidades produtivas no estado, fabricando 200 milhões de litros por ano. Desse total, pouco mais de 600 empresas caracterizam-se como organizações formais (SEBRAE, 2013).
Estudos anteriores indicam que o sistema de produção artesanal de cachaça, sobretudo em Minas Gerais, é marcado por diferentes características. Dentre elas, destacamos: a forte presença da informalidade; a diversidade em termos do nível de tecnologia, equipamentos e processos produtivos; a influência de tradições locais e regionais; a forte integração da produção de cachaça com outras atividades agropecuárias; o acesso a mercados locais, regionais, nacionais e, em alguns casos, internacionais; e a influência do Estado e de agências de pesquisa na construção de um padrão de qualidade cientificamente atestado (LIMA, SILVA e ROCHA, 2010; SILVA, 2009; COUTINHO, 2001; CRUZ, 2009).

Nesse contexto, pesquisadores reconhecem a importância da compreensão da dimensão institucional do campo da cachaça de alambique (OLIVEIRA et al., 2008; RODRIGUES NETO e FREITAS, 2012). Essa configuração é de grande relevância para se compreender certas características que marcam este campo, sobretudo no que se refere à pluralidade de sentidos e práticas construídas ao longo dos anos, especialmente após a década de 1980. Portando, a partir das características constitutivas das organizações produtoras de cachaça de alambique em MG, percebemos a atuação de diferentes atores e estruturas sociais que recebem influência de diferentes lógicas institucionais. Essas lógicas representam padrões históricos de práticas, símbolos culturais, valores e significados por meio dos quais os sujeitos produzem sentidos sobre a vida cotidiana, tomam decisões e se reproduzem (FRIEDLAND e ALFORD, 1991; THORNTON e OCASIO, 2008). Considerando o campo organizacional da cachaça artesanal em Minas Gerais, entendemos 
que as lógicas que o constituem concorrem e cooperam entre si em uma relação de pluralismo institucional (YU, 2015; GREENWOOD et al., 2011).

Todavia, uma vez observada a lacuna de estudos que exploram esse aspecto, questionamos: como estão configuradas as lógicas institucionais do campo organizacional da cachaça de alambique em Minas Gerais? Nesse sentido, traçamos como objetivo deste artigo descrever a configuração das lógicas que marcam o contexto institucional das organizações produtoras de cachaça alambique em Minas Gerais.

Para tanto, realizamos uma pesquisa de natureza interpretativa e descritiva, a partir de fontes documentais e entrevistas com atores que representam organizações que constituem esse campo. Identificamos como instituições de maior proeminência nesses espaços: a tradição, o Estado, o mercado e o conhecimento técnico-científico. A partir desta dimensão, procuramos descrever estas lógicas destacando os aspectos constitutivos de cada uma. Pela análise dos resultados, percebemos como a influência da lógica técnico-científica, sobretudo após a década de 1980, produziu efeitos nas características do campo. Essa lógica também influenciou de modo amplo nos processos de legitimação e ressignificação das lógicas do Estado, do mercado e da tradição, impactando no "saber-fazer" cachaça. Esse arranjo formou uma nova configuração institucional no estado que serve como referência para o desenvolvimento de novos negócios e oportunidades no campo da cachaça de alambique.

Além desta introdução (1), discutiremos as bases teóricas da abordagem das lógicas institucionais (2); os procedimentos metodológicos da pesquisa (3); os resultados e a discussão do trabalho (4), destacando o contexto histórico no qual a cachaça de alambique se estruturou e a configuração das lógicas que estruturam o campo da cachaça artesanal. Por fim, tecemos algumas considerações finais (5).

\section{A perspectiva das lógicas institucionais}

A perspectiva das lógicas institucionais é reconhecida como uma importante corrente de estudos do institucionalismo sociológico, ou organizacional (MOTKE, RAVANELLO e RODRIGUES, 2016). Especialmente nessa direção, essa abordagem apresenta contribuições importantes no que se refere aos efeitos das instituições nas práticas e na construção da identidade dos sujeitos (LOUNSBURY e BOXENBAUM, 2013).

Existem diversas conceituações e tradições de pesquisa envolvendo instituições (SCOTT, 2008). Entretanto, neste trabalho nos apoiaremos no texto seminal da perspectiva das lógicas institucionais, no qual, Friedland e Alford (1991) definem instituições como:

“[...] padrões de atividade supraorganizacionais enraizados em práticas materiais e sistemas simbólicos pelos quais indivíduos e organizações produzem e reproduzem suas vidas materiais e tornam suas experiências significantes" (FRIEDLAND e ALFORD, 1991, p. 232, tradução nossa).

Para esses autores, a sociedade é entendida como um sistema interinstitucional. Ou seja, é formada por diferentes instituições. Cada uma dessas apresenta um conjunto de padrões de práticas e símbolos que servem como referência para que os sujeitos construam sentidos sobre suas atividades (FRIEDLAND e ALFORD, 1991). Esses padrões referem-se às lógicas institucionais. Em um conceito desenvolvido mais adiante, Thornton e Ocasio (2008, p. 804, tradução própria) descrevem as lógicas institucionais como:

"padrões históricos, socialmente construídos de práticas materiais, hipóteses, valores, crenças e regras pelas quais os indivíduos produzem e reproduzem sua subsistência material, organizam seu tempo e espaço e dão significado à vida".

Considerando-se as diferentes instituições que permeiam um campo ou setor societal, concebemos que as lógicas institucionais coexistem e são interpretadas simultaneamente pelos sujeitos. Essa interação produz efeitos complexos que podem incorrer tanto em conflitos quanto cooperação de lógicas nas ações (GREENWOOD et al., 2011). A inter-relação de lógicas institucionais caracteriza o pluralismo institucional, fenômeno que tem sido estudado a partir de diferentes quadros teórico-metodológicos (YU, 2015, CURRY e SPYRIDONIDIS, 2016).

Nesse sentido, os sujeitos, em suas interações cotidianas, realizam ações e atividades, bem como 
constroem suas identidades a partir da interpretação das orientações referentes às múltiplas lógicas institucionais que permeiam estes espaços. Em meio a esses processos interpretativos, reconhece-se a capacidade reflexiva dos atores, o que implica na heterogeneidade nos cursos de ação. Essa dinâmica também incorre na ressignificação dos pressupostos das lógicas ao longo do tempo e na institucionalização de novos sentidos, representando mudanças no campo (SMETS e JARZABKOWSKI, 2013).

Conforme Smets, Greenswood e Lounsbury (2015), a perspectiva das lógicas institucionais é hoje o principal movimento dentro da teoria institucional sociológica. Apesar de os primeiros trabalhos terem sido desenvolvidos nos Estados Unidos, o campo hoje recebe contribuições de diversos continentes, com destaque à Europa. No Brasil, a perspectiva tem sido bem recepcionada pelos principais periódicos e eventos da área de Administração e Estudos Organizacionais (SILVA e CRUBELLATE, 2016). Desse modo, o presente trabalho contribui para a ampliação das pesquisas envolvendo pluralismo institucional e lógicas institucionais no âmbito nacional. Na próxima seção apresentaremos os procedimentos metodológicos que nos ampararam na realização desta pesquisa.

\section{Procedimentos metodológicos}

Neste estudo, optamos pelo método de pesquisa descritivo-exploratório, de natureza qualitativa, fundamentado em uma abordagem interpretativa (ALENCAR, 2007). Essa escolha permitiu a investigação, interpretação e descrição do conjunto de lógicas institucionais constitutivas do campo da cachaça de alambique em Minas Gerais. Partimos do pressuposto que os campos organizacionais são constituídos por sujeitos, elementos não humanos e instituições que interagem produzindo sentidos socialmente construídos (MACHADO-DA-SILVA, GUARIDO FILHO e ROSSONI, 2006). A adoção desse pressuposto implicou no entendimento do campo como um conjunto de atores que operam em um mesmo setor social. Esses atores são orientados por um conjunto relativamente estável de lógicas institucionais e formam uma rede de interdependência (THORNTON e OCASIO, 2008, BONFIM, GONÇALVES e ABIB, 2013). Neste artigo, consideramos como atores os sujeitos engajados em organizações que façam parte do que denominamos campo da cachaça de alambique. Entre elas destacam-se: organizações produtoras de cachaça de alambique; fornecedores; distribuidoras de bebidas; universidades e centros de pesquisa; agências governamentais como o Instituto Mineiro de Agropecuária (IMA) e o Instituto Nacional de Metrologia, Qualidade e Tecnologia (Inmetro), entre outras; associações de produtores; cooperativas etc.

Para a coleta de dados da pesquisa, utilizamos fontes documentais e realizamos entrevistas em profundidade. A partir destas técnicas de pesquisa, foi possível compreender e descrever o contexto sócio histórico dos atores e organizações produtoras de cachaça. Nesse sentido, este entendimento contribuiu de modo significativo para a apreensão das lógicas institucionais.

As fontes documentais foram coletadas a partir de documentos tais como: a) relatórios - 'Diagnóstico da cachaça de Minas Gerais' (SEBRAE, 2001), 'Cachaça Artesanal - Estudos Mercadológicos' (SEBRAE, 2013), 'Planejamento Estratégico para a Cadeia Produtiva da Cachaça' (CORS, 2014), 'Aguardente em Minas Gerais' (INDI, 1982), entre outros - b) manuais de produção (OLIVEIRA et al., 2005; MARELLI DE SOUZA et al., 2013); bem como c) reportagens de jornais, revistas e vídeos publicados em meio eletrônico. O critério para a seleção do corpus de análise foi baseado no recorte temático e a pertinência dos textos quanto ao objetivo do trabalho.

Após a coleta destes textos, procedemos uma primeira etapa de análise dos mesmos por meio do método da análise temática (BRAUN e CLARK, 2006). Este método consiste na análise recursiva e sistemática de textos, embasada em pressupostos construcionistas, por meio das etapas de: familiarização, sistematização de dados, classificação e agrupamento de temas, revisão de temas, definição de categorias de análise e análise integrativa (BRAUN e CLARK, 2006). Portanto, organizamos o corpus, procedemos a leitura do mesmo e construímos um mapa temático por meio da identificação de aspectos que marcam o contexto sócio histórico da cachaça de alambique. Assim, diferentes períodos históricos representaram temas centrais e suas características principais foram estruturadas como subtemas. A análise destes temas nos proporcionou um entendimento acerca do desenvolvimento deste setor.

Em seguida, retomamos a pesquisa de campo e coletamos dados primários a partir de atores engajados 
em organizações que constituem este campo, de modo a melhor compreender aspectos que marcam este contexto institucional. Para tanto, foram realizadas três entrevistas com sujeitos que vêm desempenhando atividades envolvendo a cachaça de alambique ao longo das últimas décadas, tendo alguns deles participado ativamente das mudanças ocorridas na dinâmica do campo. Após essa etapa, procedemos mais três entrevistas com atores produtores de cachaça de alambique que estão inseridos no campo há pelo menos 15 anos. Esses produtores também acompanharam a dinâmica institucional e nos auxiliaram a demarcar a influência das principais lógicas do campo. O critério de inclusão desses sujeitos foi definido conforme nossa percepção acerca do papel das organizações a que representam na estruturação deste campo. Esta percepção, todavia, foi construída a partir da análise das fontes bibliográficas e documentais. O Quadro 1 apresenta o perfil dos sujeitos entrevistados durante a pesquisa.

As entrevistas duraram, em média, 1 hora e 30 minutos e foram realizadas presencialmente. Os enunciados foram gravados por meio de gravador digital e posteriormente transcritos para uma ferramenta eletrônica de produção de textos. Após essa etapa, integramos todo o corpus e novamente recorremos à análise temática para nos auxiliar a demarcar e descrever as lógicas e suas características (BRAUN e CLARK, 2006). Dessa forma, procedemos nova análise do corpus e delimitamos como temas ou categorias centrais aspectos textuais que representassem as instituições de maior proeminência neste contexto. As características destas instituições foram exploradas como subtemas e constituem as lógicas institucionais presentes no campo da cachaça de alambique em Minas Gerais. Assim, destacamos os pressupostos centrais, bem como as orientações referentes às práticas e a dimensão simbólica que as lógicas oferecem aos atores do campo (FRIEDLAND e ALFORD, 1991).
É importante destacar que outras instituições e, consequentemente, outras lógicas também constituem as atividades desempenhadas no campo organizacional da cachaça de alambique (THORNTON e OCASIO, 2008). Entretanto, para que possamos entender um recorte dessa realidade, decidimos destacar aquelas lógicas que exercem maior influência. Portanto, identificamos como temas centrais as seguintes lógicas: tradição, mercado, Estado e o conhecimento técnico-científico. A construção de tipologias que representem lógicas institucionais nos campos sociais tem sido um instrumento utilizado recorrente por pesquisadores alinhados a esta perspectiva (THORNTON e OCASIO, 2008; GREENWOOD et al., 2011). A seguir, serão apresentados os resultados deste trabalho.

\section{Resultados e discussão}

Nesta seção apresentaremos os resultados deste trabalho. Primeiramente, descreveremos a contextualização histórica da produção da cachaça de alambique a partir de eventos históricos.

\subsection{O contexto histórico da produção de cachaça de alambique}

Ao se considerar a amplitude histórica da produção de cachaça brasileira, e de modo específico em Minas Gerais, é possível reconhecer diferentes atores e instituições envolvidos na configuração desse campo. Dentre eles destacamos: o Estado, produtores (formais e informais), associações e cooperativas de fabricantes, agências de apoio ao desenvolvimento de negócios, universidades etc. (SILVA, 2009; DIAS, 2016; CUNHA e SOUZA, 2012).

A cachaça começou a ser produzida no Brasil durante período colonial, por volta do século XVI,

Quadro 1. Perfil dos sujeitos entrevistados durante a pesquisa

\begin{tabular}{|l|l|}
\hline \multicolumn{1}{|c|}{ Entrevistado } & \multicolumn{1}{c|}{ Ocupação } \\
\hline Entrevistado 1 & Presidente da Associação Mineira de Produtores de Cachaça de Qualidade (Ampaq) \\
\hline Entrevistado 2 & Fiscal do Ministério da Agricultura, Pecuária e Abastecimento (Mapa) no estado de Minas Gerais \\
\hline Entrevistado 3 & Presidente do Sindicato das Indústrias de Cervejas e Bebidas em Geral do Estado de Minas Gerais (Sindibebidas) \\
\hline Entrevistado 4 & Produtor de cachaça de alambique desde 1984 \\
\hline Entrevistado 5 & Produtor de cachaça de alambique desde 1991 e consultor de projetos envolvendo a cadeia produtiva da bebida \\
\hline Entrevistado 6 & Produtor de cachaça de alambique desde 1998 \\
\hline
\end{tabular}

Fonte: Elaborado pelos autores. 
e foi um importante bem comercial à época, destinado majoritariamente ao consumo interno (SILVA, 2009). Conforme Coutinho (2001), a produção e comercialização da bebida nesse período eram realizadas à margem da lei, em pequenos estabelecimentos, e seu consumo era frequentemente direcionado à população marginalizada (escravos, mineiros, expedicionários etc.). Nessa direção, devido à rápida expansão de engenhos, a produção da cachaça foi proibida pela Coroa por desviar a mão de obra das operações principais do período (SILVA, 2015). Contudo, essas ações não implicaram na diminuição do consumo ou da produção da bebida.

Durante o século XIX, a cachaça tornou-se amplamente consumida em território nacional, sobretudo por estratos mais populares, e marginalizados, da sociedade (CHALITA, 2008). Nesse período, permanecia o interesse por parte do Estado e das elites locais em controlar a comercialização da bebida, motivados por questões fiscais e pelo receio da embriaguez desregrada. Esse cenário também perdurou durante o século XX. Especialmente por parte do Estado, pouco se incentivava a produção e o consumo da bebida.

Conforme Coutinho (2001), até o final da Segunda Guerra Mundial, o modelo de produção artesanal predominava no País. Contundo, a diminuição da produção de açúcar em engenhos, bem como o desenvolvimento de inovações tecnológicas durante a década de 1940, fomentaram a industrialização do processo. Nesse período, em decorrência da crise na indústria açucareira, foram criadas as primeiras grandes empresas fabricantes de cachaça. A partir daí foi estruturado o sistema de produção de cachaça industrial, consolidado na década de 1970. Em decorrência desse processo, marcado pelo aumento na tributação e fiscalização da produção, os fabricantes de cachaça de alambique tornaram-se cada vez mais pressionados a abandonar as atividades ou permanecer na informalidade, restritos ao mercado local e às tecnologias tradicionais (SILVA, 2009).

Apesar de esta configuração estar presente em todo o território nacional, a produção de cachaça de alambique se difundiu de modo mais amplo no estado de Minas Gerais. Em função disso, a partir da década de 1980, alguns produtores de cachaça artesanal do estado, bem como agentes de setores governamentais, começaram a se articular num movimento de reconhecimento da cachaça de alambique (SILVA, 2009). Esse processo teria como pressuposto a ressignifica- ção da bebida simbolicamente a partir da construção de novos processos produtivos e inovações tecnológicas (SOUZA, 2012). Com o objetivo de implementar essas mudanças, produtores da bebida se organizaram em Minas Gerais e criaram a Associação Mineira de Produtores de Cachaça de Qualidade (Ampaq), em 1988 (CUNHA e SOUZA, 2012).

Além disso, foram criados, no âmbito do governo do estado de Minas Gerais, programas e políticas direcionadas ao setor. Dentre esses programas, destaca-se o Programa Mineiro de Incentivo à Produção de Aguardente (Pró-Cachaça), criado pela Lei Estadual no $10.853 / 1992$ e regulamentado pelo Decreto $n \underline{ }$ 34.645/1993. O objetivo do Pró-Cachaça consistia principalmente na oferta de crédito especial para que produtores rurais criassem ou investissem em alambiques e processos de produção da bebida (SILVA, 2009). As políticas desenvolvidas em Minas também serviram como referência para que o governo federal normatizasse da produção de cachaça. Adiante, também destacamos as iniciativas por parte do Estado, produtores e organizações técnicas para elaborar critérios para a certificação de qualidade, a partir do Instituto Nacional de Metrologia, Qualidade e Tecnologia (Inmetro). Em Minas Gerais, o Instituto Mineiro de Agropecuária (IMA) figura como agência certificadora.

Em suma, nesta breve narrativa descrevemos algumas características do contexto sócio histórico da cachaça de alambique, especialmente em Minas Gerais. Adiante, discutiremos os aspectos constitutivos das principais lógicas institucionais que permeiam este campo organizacional.

\subsection{As lógicas institucionais do campo organizacional da cachaça artesanal}

Nesta subseção, serão apresentadas as lógicas institucionais que constituem o campo organizacional da cachaça de alambique considerando seus aspectos constitutivos e as relações entre as mesmas.

\subsubsection{Lógica da tradição}

Entendemos que as características referentes aos padrões de produção e consumo de cachaça construídos desde o século XVI se institucionalizaram ao longo das gerações de produtores. Nessa direção, identificamos uma lógica própria dos costumes e da 
cultura, sobretudo rural, que influencia na construção da identidade e nas atividades dos atores inseridos neste campo (THORNTON e OCASIO, 2008). Denominaremos este conjunto de práticas e elementos simbólicos como lógica da tradição.

O conceito de tradição será aqui entendido como o conjunto de atividades, símbolos e processos reproduzidos de geração para geração, sobretudo por meio da linguagem oral e normas tácitas, com caráter repetitivo, embora dinâmico. As tradições perpetuam as experiências de gerações que produziram algum tipo de conhecimento, institucionalizando-o (LUVIZOTTO, 2010; ESTEVANIM, 2008), um processo semelhante à institucionalização descrita em Berger e Luckman (2004).

Desse modo, entendemos que a lógica da tradição refere-se ao conjunto de pressupostos que tratam o "fazer cachaça" como uma atividade inerente ao meio rural e familiar. Essa lógica é objetivada a partir de uma dimensão simbólica que, dentre outros aspectos, caracteriza a bebida como uma atividade econômica complementar a outras atividades produtivas do campo. Esses sentidos também assumem que o conhecimento necessário para sua fabricação é herdado e apreendido informalmente, de modo que os processos produtivos variam em certa medida de organização para organização. Da mesma forma, como herança do período colonial, compõe a dimensão simbólica a noção de que seu consumo é marginalizado, embora essa característica tenha se relativizado ao longo das últimas décadas com o ingresso de novos consumidores de cachaça, das classes A e B. Além da dimensão simbólica, a lógica da tradição orienta práticas tais como: uso de equipamentos rudimentares; destilação em alambiques de cobre; comercialização a granel, geralmente na própria unidade produtiva; entre outras. Em nossa pesquisa, procuramos evidenciar que a lógica institucional da tradição exerce influência nos atores desse campo. Conforme Dias (2016), os produtores de cachaça de alambique em diversas regiões do País procuram reiterar e viver as memórias e o conhecimento de gerações anteriores que fabricavam a bebida seguindo um conjunto de orientações e atividades que constituem a prática do 'saber fazer cachaça'.

Segundo Silva (2015), de modo geral, o processo produtivo da cachaça de alambique desenvolvido no período colonial consistia nas seguintes etapas: a) moagem da cana-de-açúcar nos engenhos, movidos por tração animal, hidráulica ou manual; b) armazena- mento do caldo, ou mosto, em recipientes, usualmente de madeira, que ficavam dispostos "a céu aberto", nos quais era preparado o ambiente para o cultivo de leveduras (ou fermentos), geralmente à base de fubá ou farelo de arroz; c) fermentação do caldo a partir das leveduras, num processo controlado de modo empírico que poderia durar até 48 horas, gerando uma espécie de vinho; d) destilação do vinho em destiladores de cobre, denominados alambiques, que quando aquecidos por fogo a lenha, evaporavam o caldo que, por sua vez, se liquefazia na tubulação ao entrar em contato com água fria, num sistema semelhante às serpentinas; e finalmente, e) após destilada, a bebida era armazenada em recipientes de barro ou de madeira para ser comercializada ou consumida. A autora destaca que, durante a destilação, poderiam ser aproveitados três tipos de cachaça. A primeira parte, com maior concentração alcoólica, denominada cachaça de "cabeça" ou forte. A segunda parte, com menor graduação alcoólica, denominada "coração". Por fim, a terceira parte da destilação, denominada cauda ou bebida fraca, consistia de um líquido com pouca graduação alcoólica e, portanto, pouco apreciado;

Esse conjunto de atividades 'tradicionais' ainda é reproduzido, conforme evidenciado pelos produtores entrevistados nesta pesquisa. Geralmente, essas práticas são realizadas por poucas pessoas, de modo que apenas alguns indivíduos conhecem todo o processo e podem ser considerados mestres alambiqueiros (SILVA, 2015). Essa tradição do "saber fazer" cachaça é um conhecimento com forte apelo às relações familiares, sendo reproduzido de geração para geração, embora existam ressignificações de organização para organização. Essas diferenças são representadas como 'segredos', normalmente se referindo às práticas de separação das fases da destilação ou técnicas de envelhecimento (SILVA, 2009).

"[...] cada produtor tem o jeitinho dele envelhecer a cachaça, a maneira de ele envelhecer a cachaça. Então, daí a razão de às vezes uma pessoa tomar uma cachaça, tomar três cachaças diferentes, quem é expert no assunto, e que já conhece o produto, sabe diferenciar: 'Não, essa é de tal lugar, daquele produtor'" (ENTREVISTADO 6).

Esses valores e atividades, baseados na experimentação e no conhecimento empírico do "saber fazer" são 
identificados, sobretudo em organizações produtoras de cachaça de alambique em situação de informalidade (DANIEL, 2016; DIAS, 2016). O Entrevistado 1 afirma, ainda, que muitos produtores preferem permanecer nessa condição a fim de manter o conhecimento apreendido ao longo das gerações.

Como um reflexo da criação da bebida no Brasil colônia, ao longo dos séculos, muitos produtores iniciavam sua produção como um tipo de atividade secundária da indústria açucareira. Neste sentido, o Entrevistado 1 argumenta que, ainda hoje, normalmente, este perfil de pequeno produtor, além de produzir frutas, verduras e hortaliças: "[...] tem um alambiquezinho, que é pra tradição da família. E fica ali, como um negocinho na cerca, na porteira. Não ultrapassa nunca a cidade dele, não há interesse de ultrapassar" (ENTREVISTADO 1).

Ainda, as práticas de distribuição da cachaça foram marcadas pela comercialização no próprio ambiente em que a bebida era produzida ou na comercialização em pequenos varejos, atendendo ao mercado consumidor local (DANIEL, 2016; SILVA, 2015). Sendo assim, a comercialização tradicional da bebida está relacionada ao próprio espaço no qual era fabricada. A partir dessa configuração, características que remetem ao sentido estético do meio rural, tais como a arquitetura de fazendas, móveis rústicos, engenhos ou fenômenos da natureza também constituem o conjunto de pressupostos da lógica da tradição. Esses elementos são também explorados em apropriações de turismo rural envolvendo a fabricação de cachaça (BRAGA e KYIOTANI, 2015). Ademais, aspectos sociais e culturais que construíram o imaginário da tradição no espaço rural, como a religiosidade, mitos, causos ou personagens históricos, são partes constituintes da lógica da tradição no campo da cachaça (CHALITA, 2008; DIAS, 2016).

\subsubsection{Lógica do Estado}

Reconhecemos que o Estado, a partir de um conjunto de organizações e atores envolvidos em relações políticas, também construiu uma lógica. Conforme Friedland e Alford (1991) a lógica do Estado ocidental contemporâneo está relacionada à regulação da ação humana por meio da definição de normas legais e estruturas burocráticas. Ao considerar a lógica institucional do Estado no campo da cachaça, é necessário, contudo, reconhecer que a mesma foi construída ao longo dos anos à medida que as configurações e características do Estado eram transformadas.

Assim, conceituamos a lógica do Estado como um conjunto de pressupostos que orientam a racionalização e regulação das práticas de produção, distribuição e consumo da cachaça. Esses pressupostos são objetivados por meio de um nexo de práticas normativas e sentidos construídos historicamente, referentes à dimensão simbólica do Estado. De modo específico, no campo da cachaça, o Estado procura regular as atividades, porém garante meios para tributação e valorização de um produto que passa a ser tido como patrimônio cultural do País.

As iniciativas por parte do Estado de normatizar este setor remetem ao período colonial. Embora o consumo da bebida fosse amplamente difundido em todo o território nacional, os mecanismos estatais atuavam, sobretudo, como meios de repressão destas atividades. Do século XVI até meados do século XX, foram incididos diferentes tributos à produção do destilado com a finalidade de refrear seu consumo, especialmente da cachaça fabricada artesanalmente. Todavia, devido à articulação de certos atores localizados no estado de Minas Gerais, durante a década de 1980, a atuação do Estado em relação ao campo da cachaça passou por um processo de ressignificação e mudança. Este processo ficou marcado pela virada em direção à valorização do produto e reconhecimento de seu valor econômico e como patrimônio cultural do estado.

Nesse sentido, surgiram as primeiras iniciativas de regulação e normatização específicas para a cachaça de alambique, nos anos 2000. Cabe ressaltar que anteriormente, a cachaça era padronizada, por meio da Lei no 8.918 de julho de 1994, como um tipo de aguardente, sem distinção de origem, figurando entre bebidas destiladas a partir de melaço, cereais, vegetais ou rapadura, cujo teor alcóolico variasse entre 38 a 54\% (BRASIL, 1997). Posteriormente a isso, destacamos, no estado de Minas Gerais, a criação da Lei no 13.949 de julho de 2001. Esta legislação estadual procurou estabelecer "o padrão de identidade e as características do processo de elaboração da Cachaça de Minas", sobretudo a partir de padrões técnicos e amparados pela lógica do conhecimento científico (MINAS GERAIS, 2001). Como refração dessa Lei, o governo federal publicou alguns meses à frente, o Decreto no 4.062 de dezembro de 2001. Este decreto passou a definir as expressões "cachaça", 
"Brasil" e "Cachaça do Brasil" como indicações geográficas do País, além de estabelecer outras providências (BRASIL, 2001). No entanto, apesar da legislação estadual em MG, a cachaça ainda não era regulamentada junto à União. Foi a partir do Decreto no 4.851 de outubro de 2003 que os critérios para o reconhecimento da bebida como "cachaça" foram estabelecidos, embora não existisse uma distinção entre a cachaça de alambique e a cachaça "industrial" (BRASIL, 2003). As normas para a produção de cachaça foram novamente definidas a partir do Decreto no 6.871 de junho de 2009. O decreto estabeleceu novos critérios para a padronização, classificação, registro, inspeção, produção e a fiscalização da bebida, diferenciando certos aspectos da produção de cachaça de outros destilados (BRASIL, 2009). Em Minas Gerais, a Lei no 16.688 de janeiro de 2007 declarou o processo de fabricação de cachaça de alambique como patrimônio cultural do estado.

A lógica do Estado também orienta um conjunto de práticas que direcionam à conformidade e ao controle da informalidade a partir da fiscalização das atividades produtivas. Esta prática já era recorrente no período colonial, quando a fabricação e consumo da bebida eram proibidos ou então tributados. Contudo, essa configuração passaria por mudanças após o reconhecimento e normatização da cachaça, incluindo a produção artesanal. Nessa direção, o Ministério da Agricultura, Pecuária e Abastecimento (Mapa), órgão responsável pela fiscalização, começou a atuar com maior ênfase na orientação das atividades, para além dos aspectos punitivos. Atualmente, conforme alguns dos informantes da pesquisa, os fiscais do Mapa, ao realizarem suas visitas, procuram orientar os produtores a atuarem conforme as "Boas Práticas de Produção".

“[...] No início [das atividades da organização] eu via [a fiscalização] com maus olhos, certo? Porque eu não tinha praticamente conhecimento técnico nenhum. Mas depois que eu fui convivendo com tudo e eu vi que são necessários [...] no sentido de incentivar, ajudar a dar assistência para nós. Precisava abaixar um pouco a taxa de imposto, mas quer dizer, isso não é com eles [os fiscais]. É com o Estado. [...] Mas de uma certa época pra cá passei a ver com outros olhos. [...] A gente tem que melhorar, no sentido de qualidade, e a gente procura isso" (ENTREVISTADO 4).
Adiante, a conformidade à tributação consiste num dos aspectos de maior conflito e controvérsia no campo da cachaça de alambique. Como Santiago (2007) argumenta, não existe uma distinção entre a tributação de produtores de cachaça de alambique e as grandes indústrias de cachaça. Essa característica acaba onerando excessivamente a atividade dos primeiros, que em sua maioria são microempresários. Nesse sentido, ressaltamos que a alta carga tributária representa uma barreira para a formalização de produtores:

“O que eu entendo é que a maior parte da informalidade, algumas exigências do Ministério da Agricultura, algumas adaptações que têm que ser feitas, mas a grande maioria é imposto, da cachaça, do IPI [Imposto sobre Produtos Industrializados]..." (ENTREVISTADO 2).

Entretanto, se na direção da tributação, a lógica do Estado exerce influência no sentido restritivo, esta lógica, por outro lado, também tem incorporada em sua dimensão simbólica o interesse na exploração da cachaça como patrimônio cultural, cuja produção deve ser incentivada. Este processo pode ser evidenciado por meio da criação de políticas tais como o Pró-Cachaça. Enquadram-se ainda como políticas públicas a criação de mecanismos e programas de avaliação de conformidade e certificação voluntária de organizações produtoras de cachaça de alambique (SORATTO et al., 2007; BRAGA e KIYOTANI, 2015).

\subsubsection{Lógica do mercado}

Entendemos que a lógica institucional do mercado presente no campo da cachaça de alambique refere-se aos pressupostos que orientam os atores quanto às relações de trocas. Dentre outros aspectos, a lógica de mercado orienta os sujeitos a partir de sentidos relacionados à ressignificação do consumo da bebida, ao potencial de inserção dos negócios no mercado competitivo de bebidas nacional e internacional e à busca por sobrevivência e lucratividade. Por sua vez, esta lógica é objetivada por meio de práticas tais como a exploração da distinção social, as exportações e os processos produtivos que visam a eficiência nas operações.

O conceito de mercado por nós empregado está relacionado à proposta weberiana de um espaço construído socialmente. Nesse espaço, uma pluralidade de 
agentes interessados competem por oportunidades de trocas imersas em uma dimensão política, constituída por diferentes racionalidades (RAUD-MATTEDI, 2005). Conforme Friedland e Alford (1991), a lógica de mercado está presente em qualquer sociedade ou espaço onde exista a competição entre atores para a realização de trocas. Porém, sua imersão no campo varia conforme a configuração de outras lógicas e do contexto sócio histórico.

No campo da cachaça, desde a criação da bebida no século XVI, os atores produtores competiam para a realização de trocas com os consumidores da época, embora ainda não existisse um sistema de comercialização bem estruturado. Essas trocas aconteciam muitas vezes por meio do escambo, uma vez que a cachaça servia como moeda de troca para a obtenção de escravos ou alimentos (SILVA, 2015). Durante o século XIX até meados do século $X X$, a cachaça de alambique era produzida e consumida sobretudo por pessoas de grupos marginalizados. Nesse período, a bebida era comercializada em pequenos estabelecimentos ou no próprio espaço em que era fabricada (COUTINHO, 2001).

Contudo, a partir da década de 1980, a lógica de mercado incorporou em seu sistema simbólico e nas práticas orientadas por esta as noções de distinção social da cachaça de alambique, eficiência na produção, exportações, entre outras. As mudanças que marcaram o contexto produtivo da cachaça de alambique em Minas Gerais tiveram como influência a identificação de um perfil de consumidores que se diferenciavam daqueles historicamente marginalizados. Esses sujeitos representavam pessoas com maior renda que reconheciam a cachaça produzida "artesanalmente" como um destilado de maior qualidade comparado à cachaça industrial (SILVA, 2009). Estes consumidores estariam dispostos a pagar um preço maior para consumir a cachaça de alambique (CRUZ, 2009).

Neste sentido, muitas atividades foram desenvolvidas visando à promoção da cachaça de alambique como uma bebida de qualidade superior (percebida por um padrão cientificamente legitimado). Dentre estas atividades destacam-se a) a criação de linhas diferenciadas da bebida; b) fabricação de cachaças premium, envelhecidas durante longos períodos de tempo tais como outros destilados de alta distinção; c) a formação de profissionais especialistas na degustação de cachaça, os denominados cachacier (termo utilizado em referência ao especialista em vinhos: sommelier); d) a comercialização da bebida em espaços luxuosos tais como restaurantes gourmet; e) a realização de campanhas publicitárias que posicionavam as cachaças de alambique para perfis de consumidores de alta renda; entre outras (CRUZ, 2009; CUNHA e SOUZA, 2012; BRAGA e KYIOTANI, 2015). Essas práticas e orientações são reproduzidas principalmente por publicações em revistas, estudos e dossiês do setor (SEBRAE, 2001, 2013; CORS, 2014).

Outro aspecto constitutivo da lógica de mercado no campo da cachaça de alambique é a orientação para a expansão do mercado de atuação dos produtores, sobretudo por meio das exportações da bebida. Essa constatação está relacionada à própria criação de um padrão de distinção da cachaça com fins de alcançar potenciais clientes com maior poder aquisitivo, dispostos a pagar mais caro pela bebida (BRAGA e KYIOTANI, 2015).

Todavia, para que os sujeitos produtores possam inserir neste mercado de forma competitiva e sustentável, torna-se necessário uma orientação pela eficiência na produção. Essa constatação mais uma vez está relacionada à competição com a cachaça industrial e seus efeitos já expostos neste artigo. Dessa forma, refere-se à percepção de que processos produtivos eficientes incorreriam no menor consumo de recursos para a fabricação da bebida. Consequentemente, essas medidas representariam maiores ganhos de custos, representando maior lucratividade ou maior possibilidade de competição da bebida junto a outros destilados e à cachaça industrial (LIMA, SILVA e ROCHA, 2010).

\subsubsection{Lógica técnico-científica}

Por fim, discutiremos as características constitutivas de uma lógica institucional cuja influência no campo da cachaça de alambique tem se tornado cada vez mais abrangente. Essa lógica é baseada no conjunto de instituições do conhecimento científico e em sua legitimidade nos campos sociais. Nesse sentido, a denominada lógica técnico-científica provê os pressupostos relacionados à construção de um padrão de qualidade e de práticas de produção cientificamente legitimadas para a bebida. Esses pressupostos são reproduzidos a partir de orientações que atribuem o conhecimento científico como um meio de se alcançar a distinção social da bebida e garantir a saúde alimentar do consumidor. Por sua vez, essa lógica é objetivada 
por práticas tais como o desenvolvimento de pesquisas científicas, programas de certificação de qualidade, realização de cursos técnicos, entre outras.

Primeiramente, destacamos que o sentido principal dessa lógica está relacionado à percepção/reconhecimento do conhecimento científico como uma instituição de grande legitimidade na sociedade ocidental (FRIEDLAND e ALFORD, 1991; MURRAY, 2010). Assim, caracterizamos como conhecimento técnico-científico o conjunto de práticas e normas que direcionam a produção de conhecimento com base em métodos legitimados por sujeitos de formação acadêmica ou científica. De forma específica, o conhecimento científico produzido no campo da cachaça relaciona-se diretamente ao conhecimento produzido por cientistas, sobretudo de áreas como as ciências exatas, naturais e sociais aplicadas.

A partir de nossa pesquisa, observamos que a lógica técnico-científica foi construída e atuou diretamente na consolidação das mudanças no campo após a década de 1980. Como evidência, o "Diagnóstico da Cachaça em Minas Gerais" (SEBRAE, 2001), mostrava que a principal característica deste campo era a ausência de condições técnicas de trabalho e de higiene na produção de cachaça. Tais aspectos também foram observados em "Aguardente em Minas Gerais" (INDI, 1982) e demais diagnósticos que indicavam o potencial de exploração dessa atividade no estado durante as décadas de 1980 e 1990.

Então, pesquisadores e organizações de ensino e pesquisa foram envolvidos em atividades científicas orientadas para a construção de um padrão de qualidade. Esperava-se que esse padrão fosse legitimado por pares nestas agências e que passasse a ser reconhecido pelos produtores e consumidores da bebida (COUTINHO, 2001; SILVA, 2009).

As práticas e a dimensão simbólica da lógica técnico-científica, ao longo dos anos, direcionaram o desenvolvimento de um conjunto de atividades que constituem o atual processo produtivo da bebida. Notadamente, essas práticas apresentam diferenças significativas em relação ao processo baseado na tradição (COUTINHO, 2003) e são discutidas detalhadamente em manuais direcionados aos produtores de cachaça. Dentre esses textos, destacamos o "Manual de Boas Práticas Ambientais e de Produção" (OLIVEIRA et al., 2005). Esse manual dispõe sobre um conjunto de práticas ideais para a fabricação de cachaça no estado de Minas Gerais, publicado pela Secretaria de Estado de Meio Ambiente e Desenvolvimento Sustentável (SEMAD). Nessa direção, pesquisadores da Esalq publicaram em 2013 o manual "Produção de cachaça de qualidade" (MARELLI DE SOUZA et al., 2013). Contudo, ressaltamos que uma quantidade substantiva de textos têm sido publicados com o objetivo de reproduzir as características da lógica técnico-científica na produção de cachaça de alambique.

Dentre as principais características e práticas dessa lógica, a formulação de programas de certificação está diretamente relacionada à reprodução do conhecimento técnico-científico (SORATTO et al., 2007). Neste caso, a certificação da cachaça de alambique representa uma indicação simbólica de que determinada marca ou organização atende os requisitos de composição química e a estrutura de fabricação da bebida (CARNEIRO et al., 2010). Dentre os aspectos avaliados pelos programas de certificação figuram a higiene, a saúde alimentar, a segurança no trabalho e o respeito ao meio ambiente (IMA, 2016). Os programas de certificação da cachaça de alambique, como já destacamos, são auditados por agências governamentais ou não governamentais, tais como Inmetro, IMA, Ampaq, Associação de Certificação Instituto Biodinâmico (IBD), entre outros.

\subsection{O pluralismo institucional no campo da cachaça de alambique}

A partir da investigação do contexto sócio histórico do campo organizacional da cachaça de alambique foi possível identificar tipologias que representam as principais lógicas institucionais deste arranjo, destacando seus aspectos constitutivos. As principais características destas lógicas estão representadas no Quadro 2. Em nossa análise, consideramos que os atores tomam como referência diferentes orientações destas tipologias a depender do contexto em que estão inseridos (YU, 2015; GREENWOOD et al., 2011; BESHAROV e SMITH, 2014). Logo, reconhecemos que estas lógicas institucionais são interpretadas de forma plural. Isso nos auxilia a compreender como certos eventos ou características do campo foram se desenvolvendo ao longo do tempo (SMETS et al., 2015; LEE e LOUNSBURY, 2015). 


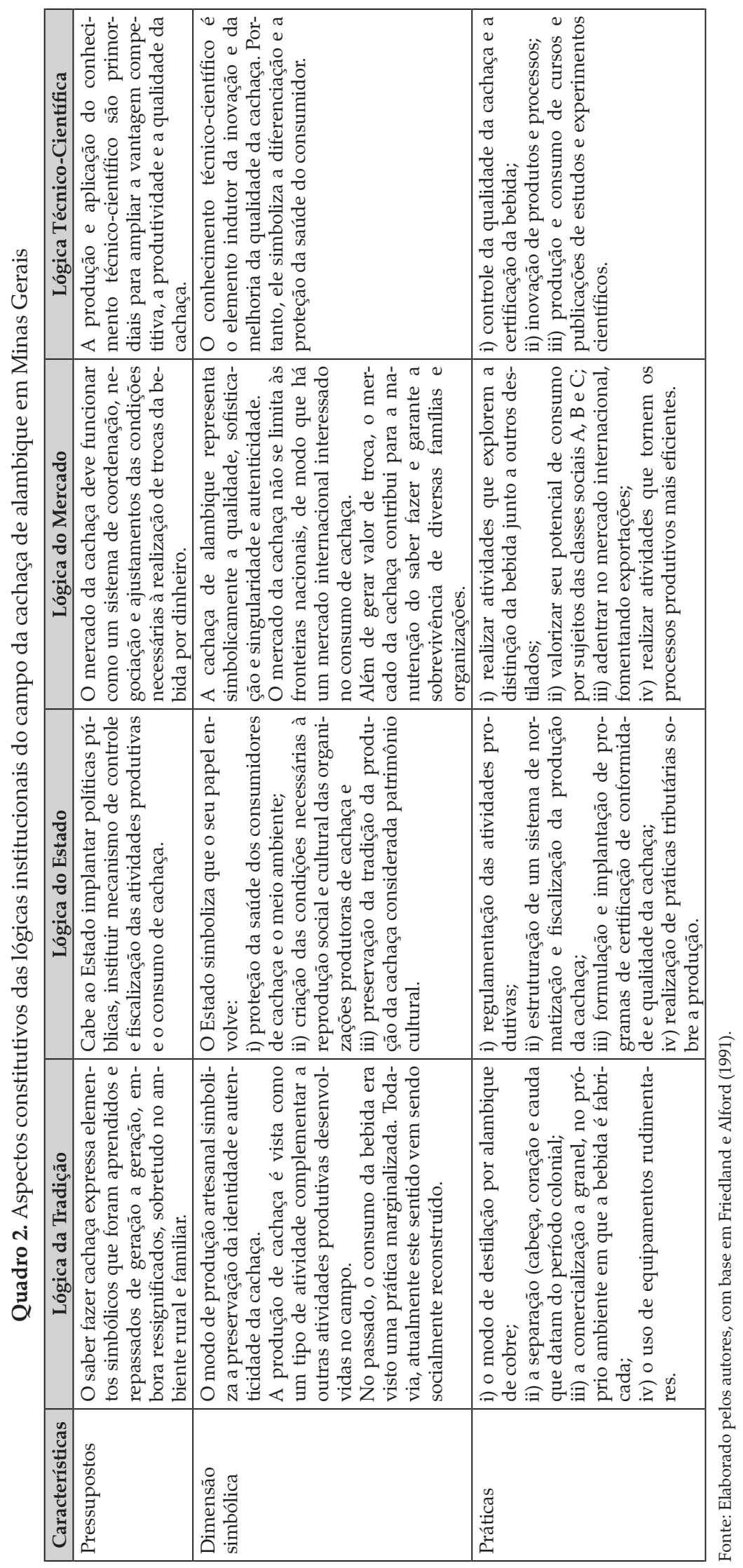


De modo geral, percebemos que a lógica da tradição ainda exerce forte influência nas ações dos atores. Aspectos simbólicos que remetem à dimensão "rural" estão presentes em diferentes características que envolvem a cachaça de alambique, seja em rótulos, embalagens, campanhas publicitárias, seja em unidades produtivas, trajetória dos atores etc. (COUTINHO, 2003). Entretanto, certos traços da lógica da tradição têm sido ressignificados quando interpretados em conjunto com outras orientações, sobretudo a partir da produção de sentidos envolvendo as lógicas do mercado e técnico-científica.

Conforme Silva (2009) e Chalita (2008), as transformações que marcaram este campo desde a década de 1980 foram baseadas na reformulação de práticas tradicionais com base em padrões técnico-científicos. Nesse sentido, o apoio na lógica técnico-científica por parte dos atores buscava legitimar a distinção da bebida para consumidores cujo perfil socioeconômico diferia dos consumidores tradicionais.

Os sujeitos produtores envolvidos nesse processo recorreram ao Estado, reconstruindo os aspectos constitutivos dessa lógica, para que políticas públicas e marcos regulatórios fossem desenvolvidos. Essas práticas normativas procuravam, entre outros aspectos institucionalizar o padrão de qualidade cientifico que os atores pretendiam implementar (SILVA, 2009; COUTINHO, 2003). Além disso, a "nova" lógica do Estado passou a orientar a fiscalização das organizações, o combate à informalidade e o desenvolvimento de programas de certificação. Novamente, esses eventos caracterizam a inter-relação das lógicas institucionais em um campo institucional plural (YU, 2015).

$\mathrm{Na}$ dimensão mercadológica, a lógica técnico-científica provê legitimidade às práticas de consumo por parte de certos perfis de consumidores das classes sociais A e B, que historicamente pouco adquiriam a bebida. O Entrevistado 4 afirma que sua estrutura de produção baseada essencialmente na conformação de normas e padrões técnico-científicos tem atraído outro perfil de clientes.

"Você tem hoje no mercado consumidor as classes A e B, certo? Cachaça no passado era um produto de classe C e D. Hoje não, hoje você tem o consumidor de alto nível financeiro. Então é diferente. Se você tem uma estrutura capaz de atender esse tipo de público, ele vai te procurar" (ENTREVISTADO 4).

Este tipo de relação também tem sido observado em outros campos de bebidas. Conforme Hills, Voronov e Hinnings (2013), até 1988, os vinhos produzidos na província de Ontario, no Canadá, eram orientados, sobretudo por uma lógica de "produção alcoólica", voltada ao consumo de massa, semelhante à produção de cachaça tradicional. Após o estabelecimento de um acordo de negociação de vinhos com os Estados Unidos, alguns produtores passaram a empenhar esforços na produção a partir de uma nova lógica de "produção vitivinícula". Esta lógica era orientada pela fabricação da bebida obedecendo a padrões internacionalmente legitimados de qualidade e uma preocupação com o sentido estético e simbólico do vinho de alta classe. Os atores que passaram a aderir à produção de vinhos finos começaram a desenvolver estratégias para a propagação da nova lógica e relegação da lógica anterior.

Em nossa análise, percebemos esse fenômeno se reproduzir em certos casos do campo organizacional da cachaça de alambique. Alguns produtores orientados pelas lógicas de mercado e técnico-científica, procuram apresentar retóricas que deslegitimam a cachaça produzida essencialmente a partir da lógica da tradição, marcada pela informalidade e pelo uso de procedimentos tidos como "sujos" ou "enganadores".

“[...] produzir cachaça não é difícil. A levedura te cobra alguma coisa, mas se você der condição para ela, ela vai te dar o retorno. Agora se você não der, igual a gente vê por aí... levedura gosta de ambiente sadio, limpo. Aí você vai nesses alambiques informais e é uma podridão danada, tudo quanto é porcaria você vê. Já vi cada coisa aí que você nem imagina o que possa ser. E o cara diz que produz a melhor cachaça da região" (ENTREVISTADO 5).

No entanto, também é perceptível que muitos produtores empregam sentidos referentes a diferentes lógicas na construção de suas estratégias, incluindo o reconhecimento de aspectos da lógica da tradição como relevantes na estruturação do campo. Essa imbricação também se reflete nas apropriações da dimensão tradicional, juntamente à lógica de mercado, em práticas de 
turismo rural que exploram a produção e o consumo de cachaça (BRAGA e KYOTANI, 2015; CORS, 2014).

Estes resultados sugerem que o pluralismo institucional, no caso das lógicas técnico-científica e da tradição, constituiu elementos fundamentais para a reconfiguração do campo. As diferentes lógicas foram e são interpretadas pelos sujeitos à medida que uma instituição permitiu a reconstrução de outra, aumentando sua influência (LEE e LOUNSBURY, 2015; SMETS et al., 2015).

\section{Considerações finais}

Este trabalho teve como objetivo descrever a configuração das lógicas que marcam o contexto institucional das organizações produtoras de cachaça de alambique em Minas Gerais. Desta forma, procuramos resgatar o contexto sócio-histórico da bebida com base em fontes bibliográficas, documentais e entrevistas realizadas com atores que representam organizações do campo. Assim, identificamos e descrevemos quatro principais tipologias de lógicas institucionais, a saber: tradição, mercado, Estado e técnico-científica.

Apresentamos os pressupostos que orientam a dimensão simbólica e as práticas que constituem cada tipologia discutida, destacando o processo de construção das mesmas ao longo do tempo. Deste modo, do ponto de vista teórico, compreendemos como os sentidos que marcam estas lógicas institucionais foram construídos ao longo dos anos de forma imbricada.

Nossas análises evidenciaram que este campo é permeado por diferentes lógicas que exercem influência (e são influenciadas) de modo relacional. A lógica da tradição refere-se ao conjunto de sentidos que tomam como referência a tradição na produção e consumo de cachaça, construídos e ressignificados desde o período colonial. A lógica do Estado atribui os mecanismos de normatização e regulação das atividades deste campo. Por sua vez, a lógica do mercado diz respeito aos pressupostos que marcam as trocas realizadas entre os atores. Finalmente, a lógica técnico-científica orienta a dimensão simbólica e material baseada no conhecimento científico, que é tomado como fonte de legitimação para a construção de um padrão de qualidade que distingue a bebida.

Estas lógicas servem de referência para os processos interpretativos dos atores do campo à medida que realizam interações e socializam práticas e elementos simbólicos característicos destas instituições. Nesta discussão, demonstramos, também, como a dinâmica institucional é situada no tempo e no espaço. Muitas das características que representam esse ambiente atualmente foram construídas ao longo dos anos, evidenciando como as próprias instituições mudam seus aspectos constituintes. Este aspecto nos pareceu claro à medida que analisamos a construção dos sentidos referentes às lógicas do Estado e de mercado, cuja mudança foi devida essencialmente à maior influência da lógica técnico-científica no campo.

Neste trabalho também observamos que a interpretação destas lógicas é realizada pelos sujeitos de forma múltipla e plural. Ou seja, em suas estratégias e práticas cotidianas, os atores do campo empregam sentidos alinhados a diferentes lógicas, de modo que a influência de uma lógica possibilita a legitimação de outra. Exploramos esta relação, sobretudo no que se refere a práticas de inserção mercadológica que incorporam aspectos da lógica da tradição imbricados à lógica técnico-científica.

Em relação às contribuições práticas e gerenciais desse trabalho, destacamos que a descrição da configuração institucional da cachaça de alambique permite uma leitura e análise das estruturas e padrões institucionalizados que marcam este setor. Neste sentido, este conhecimento possibilita o entendimento de certos eventos e os papéis dos diferentes atores que os constituem. Este tipo de investigação também serve como um instrumento de reflexão por parte dos produtores e agentes do campo, uma vez que foi evidenciada a pluralidade deste espaço e o caráter histórico e situado do mesmo. Sugerimos que não existem lógicas institucionais dominantes e que as atividades desempenhadas pelos atores não necessariamente se atêm a um único direcionamento ou pressão isomórfica.

É importante ressaltar que não pretendemos esgotar todas as relações entre as lógicas institucionais apresentadas. Além disso, entendemos que é possível apresentar outros tipos de padrões institucionalizados que possuem sua própria lógica de influência ao campo aqui investigado. Nessa direção, essa discussão pode ser aprimorada a partir da incorporação de outros tipos de elementos simbólicos e práticas que orientam a ação e o desenvolvimento de estratégias por meio das tipologias apresentadas. Por fim, demarcamos também que a incorporação de narrativas de outros sujeitos que 
constituem este campo pode implicar na apresentação de sentidos complementares aos aqui apresentados.

Tendo em vista que a argumentação desenvolvida neste estudo teve como intuito demonstrar a dinâmica institucional do campo organizacional da cachaça artesanal, sob a abordagem de lógicas institucionais, sugere-se como agenda de pesquisa:

1. A exploração de outros tipos de relações, ou mesmo lógicas que não foram tratadas aqui, de modo a contribuir para o conhecimento em torno da cachaça de alambique;

2. A investigação desta configuração institucional em casos empíricos que compreendam diferentes organizações produtoras de cachaça de alambique, especialmente em Minas Gerais;

3. A utilização de outras abordagens teóricas para investigar a relação entre os atores envolvidos na produção e consumo da cachaça artesanal, tais como a sociologia reflexiva de Pierre Bourdieu; a sociologia pragmática francesa e outras correntes da própria teoria institucional, como o institucionalismo histórico.

Entendemos, por fim, que a cachaça de alambique representa um importante símbolo da identidade nacional brasileira, e de modo específico no estado de Minas Gerais. Esse produto traz incorporado nas práticas de fabricação e consumo um amplo conjunto de elementos simbólicos que representam as transformações da bebida desde o período colonial até a atualidade. Nesse sentido, a cachaça, a partir da mobilização de diferentes atores junto ao Estado (cuja atuação se deu no estabelecimento de dispositivos normativos e de políticas públicas) e à academia, têm impactado positivamente no estabelecimento de relações econômicas. Essas relações perpassam tanto grandes produtores (em organizações industriais de grande escala), quanto sujeitos cuja atuação se dá em pequena escala, como um tipo de complemento ou mesmo subsistência. No que se refere a esse perfil de produtores, o potencial econômico da bebida também tem muito a oferecer em termos de desenvolvimentos local e rural, especialmente ao se considerar a bebida produzida conforme padrões específicos de qualidade, que permitem melhor competição do destilado nos contextos nacional e internacional. Portanto, é fundamental que mais estudos relatem as possibilidades e desafios do setor produtivo da cachaça de alambique.

\section{Referências}

AMPAQ - Associação Mineira de Produtores de Cachaça de Qualidade. Legislação e Tributação, 2016. Disponível em: <http://www.ampaq.com.br/?op=conteudo\&id $=1$ 37\&menuId=147>. Acesso em: 03 dez. 2016.

BERGER, P. L. e LUCKMANN, T. A construção social da realidade: um livro sobre a sociologia do conhecimento. 2. ed. Dinalivro: Lisboa, 2004.

BESHAROV, M. L. e SMITH, W. K. Multiple institutional logics in organizations: explaining their varied nature and implications. Academy of Management Review, v. 39, n. 3, p. 364-381, 2014.

BONFIM, L. R. C., ABIB, G. e GONÇALVES, S. A. Lógicas institucionais no estudo da estratégia como prática: uma proposta de relação entre o conceito e a abordagem. In: 8th Iberoamerican Academy Conference, 2013, São Paulo - SP. Anais do 8th Iberoamerican Academy Conference, Vol. 8, 2013.

BRAGA, M. V. F. e KIYOTANI, I. B. A cachaça como patrimônio: turismo cultura e sabor. Revista de Turismo Contemporâneo-RTC, v. 3, n. 2, p. 254-275, jul./dez. 2015.

BRASIL. Ministério da Agricultura. Decreto no 2.314 de 4 de setembro de B. CEPPA, Curitiba, v. 22, n. 1, jan./jun. 200495 1997. Regulamenta a Lei no 8.918 de 14 de julho de 1994, que dispõe sobre a padronização, a classificação, o registro, a inspeção, a produção e a fiscalização de bebidas. Diário Oficial [da] República Federativa do Brasil, Brasília, 5 set. 1997.

. Decreto no 4062, de 21 de dezembro de 2001. Define as expressões "cachaça", "Brasil e "cachaça do Brasil" como indicações geográficas e dá outras providências. Diário Oficial da República Federativa do Brasil, Brasília, 22 dez. 2001.

. Decreto no 4.851 , de 2 de outubro de 2003. Altera dispositivos do Regulamento aprovado pelo Decreto no 2.314, de 4 de setembro de 1997, que dispõe sobre a padronização, a classificação, o registro, a inspeção, a produção e a fiscalização de bebidas. Diário Oficial da República Federativa do Brasil, Brasília, 2 out. 2003.

. Decreto $\mathrm{n}^{\mathrm{o}}$ 6.871, de 4 de junho de 2009. Regulamenta a Lei no 8.918, de 14 de julho de 1994, que dispõe sobre a padronização, a classificação, o registro, a inspeção, a produção e a fiscalização de bebidas. Diário Oficial da República Federativa do Brasil, Brasília, 4 jun. 2009.

. Lei Complementar no 123 , de 14 de dezembro de 2006. Diário Oficial da República Federativa do Brasil, Brasília, 14 dez. 2006. 
. Instrução Normativa no 13 , de 29 de junho de 2005. Aprova o Regulamento Técnico para Fixação dos Padrões de Identidade e Qualidade para Aguardente de Cana e para Cachaça. Diário Oficial da República Federativa do Brasil, Brasília, 30 jun. 2005, Seção 1, Página 3.

BRAUN, V. e CLARKE, V. Using thematic analysis in psychology. Qualitative Research in Psychology, v. 3, n. 2, p. 77-101, 2006.

CARNEIRO, J. de D. S. et al. Opiniões e atitudes dos consumidores em relação a embalagens e rótulos de cachaça. Ciência e Tecnologia de Alimentos, v. 30, n. 1, p. 669-673, 2010.

CHALITA, M. A. N.. A construção social e econômica do gosto e da preferência, o valor simbólico da mercadoria e o desempenho das exportações de cachaça. Informações Econômicas, v. 38, n. 5, p. 17-29, maio 2008.

CORS - Center for Organization Studies. Planejamento estratégico para a cadeia produtiva da cachaça. São Paulo: USP, 2014.

COUTINHO, E. P. Dinâmica da modernização do setor de produção de aguardente de cana-de-açúcar no Brasil: construindo uma cachaça de qualidade. 2001. Tese (Doutorado) - Universidade Federal do Rio de Janeiro, Rio de Janeiro, 2001.

. Aspectos da evolução do mercado da cachaça. In: XXIII Encontro Nac. de Eng. de Produção. Anais... Ouro Preto, MG, Brasil, 21 a 24 out. 2003.

CRUZ, R. C. Narrativas de consumidores de cachaça $e$ representações sociais: construção negociada de significados. 2009. 131 f. Dissertação (Mestrado) Universidade Federal de Minas Gerais, Belo Horizonte, 2009.

CUNHA, M. N. e SOUZA, V. L. Publicidade, construção e reconstrução social: um estudo sobre o lugar das práticas de consumo e da publicidade nas transformações na imagem da cachaça no Brasil. In: XVII Congresso de Ciências da Comunicação na Região Sudeste - Ouro Preto - MG, 2012. Anais... Intecom: Ouro Preto, 2012.

CURRIE, G. e SPYRIDONIDIS, D. Interpretation of multiple institutional logics on the ground: actors' position, their agency and situational constraints in professionalized contexts. Organization studies, v. 37, n. 1, p. 77-97, 2016.

DANIEL, R. C. Pequena produção de cachaça no interior paulista: a informalidade em questão. 2016. 164 f.
Dissertação (Mestrado) - Faculdade de Ciências e Letras - UNESP, Araraquara, 2016.

DIAS, N. C. Entre Memórias Coletivas e Significações: o saber-fazer da cachaça artesanal de Paraty (RJ) como patrimônio cultural local. In: XVII Encontro de História da Anpuh-Rio, 2016, Nova Iguaçu. Anais..., 2016. p. 1-13.

ESTEVANIM, M. A cachaça como produto da cultura maranhense. Revista Cambiassu, ano XVII, n. 4. p. 158273, 2008.

FRIEDLAND, R. e ALFORD, R. R. Bringing society back in: symbols, practices and institutional contradiction. In: POWELL, W. W. e DIMAGGIO, P. J. The new institutionalism in organizational analysis: 232263. Chicago, IL: The University of Chicago Press, 1991.

GREENWOOD, R. et al. Institutional complexity and organizational responses. The Academy of Management Annals, v. 5, n. 1, p. 317-371, 2011.

HILLS, S., VORONOV, M. e HINNINGS, C. R. Putting new wine in old bottles: utilizing rhetorical history to overcome stigma associated with a previously dominant logic. In: Institutional Logics in Action, Part B (Research in the Sociology of Organizations, Volume 39 Part B) Emerald Group Publishing Limited, v. 39, p. 99-137, 2013.

IMA - Institutito Mineiro de Agropecuária. Certificação Cachaça, 2016. Disponível em: <http://www.ima. mg.gov.br/certificacao/cachaca >.

INDI - Instituto de Desenvolvimento Integrado de Minas Gerais. Aguardente em Minas Gerais: estudo setorial. Belo Horizonte: INDI, 1982. 90p.

LEE, M. P. e LOUNSBURY, M. Filtering institutional logics: community logic variation and differential responses to the institutional complexity of toxic waste. Organization Science, v. 26, n. 3, p. 847-866, 2015.

LIMA, I. B., SILVA, L. H. e ROCHA, L. E. V. “Cachaça de minas" e desenvolvimento rural: Uma analise para o cooperativismo e agronegócio. Embrapa, 2010. Disponível em: < http://www.agencia.cnptia.embrapa. $\mathrm{br} />$.

LIMA, J. B. Oportunidades, identificação, exploração e construção de nova oportunidade no processo de exploração da produção de cachaça em Minas Gerais: o caso da cachaça Bocaina (Lavras-MG). In: MACHADO, H. P. V. (Org.). Empreendedorismo, oportunidades e cultura: seleção de casos no contexto brasileiro. Maringá: Eduem, 2013, p. 67-90.

LUVIZOTTO, C. K. As tradições gaúchas e sua racionalização na modernidade tardia [online]. São Paulo: 
Editora UNESP; São Paulo: Cultura Acadêmica, 2010. $140 \mathrm{p}$.

MACHADO-DA-SILVA, C. L., GUARIDO FILHO, E. R. e ROSSONI, L. Campos organizacionais: seis diferentes leituras e a perspectiva de estruturação. Revista de Administração Contemporânea, ed. esp., v. 10, p. 159-196, 2006.

MARELLI DE SOUZA, L. et al. Produção de cachaça de qualidade. Piracicaba - ESALQ, 2013, 72p.

MINAS GERAIS. Decreto no 34.645, de 14 de abril de 1993. Regulamenta a Lei no 10.853 , de 4 de agosto de 1992, que cria o Programa Mineiro de Incentivo à Produção de Aguardente - Pró-Cachaça, e dá outras providências. Diário do Executivo - "Minas Gerais", 15 abr. 1993.

. Lei no 13.949 , de 11 de julho de 2001. Estabelece o padrão de identidade e as características do processo de elaboração da Cachaça de Minas e dá outras providências. Diário do Executivo - "Minas Gerais", 12 jul. 2001.

MOTKE, R. D., RAVANELLO, F. S. e RODRIGUES, G. O. Teoria institucional: um estudo bibliométrico da última década na Web of Science. CONTEXTUS Revista Contemporânea de Economia e Gestão, v. 14, n. 2, 2016.

MURRAY, F. The oncomouse that roared: hybrid exchange strategies as a source of distinction at the boundary of overlapping institutions1. American Journal of Sociology, v. 116, n. 2, p. 341-388, 2010.

OLIVEIRA, A. R. D. et al. Análise da cadeia produtiva da cachaça em Minas Gerais sob a ótica da Economia dos Custos de Transação. Revista Custos e @gronegócio, v. 4, n. 3, p. 72-97, 2008.

OLIVEIRA, C. R. et al. Cachaça de alambique: manual de boas práticas ambientais e de produção. Convênio de Cooperação Técnica SEAPA / SEMAD / AMPAQ / FEAM / IMA, 2005.

OLIVEIRA, L. M. B. Inovação em um produto típico: a cachaça artesanal certificada de Minas Gerais. 2012. 227 f. Dissertação (Mestrado) - Universidade de Trásos-Montes e Alto Douro, Vila Real, Portugal, 2012.

OLIVEIRA, R. E. S. et al. Perfil e hábitos dos consumidores de cachaça no Estado da Paraíba. Semina: Ciências Agrárias, Londrina, v. 33, n. 1, p. 259-270, 2012.

PAIVA, A. L. P., SOUZA, R. B. e BARRETO, I. D. C. Perfil Das Exportações Brasileiras de Cachaça: Traços da Influência do Estado no Setor. In: 54을 Congresso da Sociedade Brasileira de Economia, Administração e
Sociologia Rural. 2016. Anais... 14 a 17 de ago., Maceió, Alagoas, Brasil, 2016

RAUD-MATTEDI, C. A construção social do mercado em Durkheim e Weber: análise do papel das instituições na sociologia econômica clássica. Revista Brasileira de Ciências Sociais, v. 20, n. 57, p. 127-142, 2005.

RODRIGUES NETO, A. e FREITAS, L. S. Análise do processo de adaptação estratégica de uma empresa produtora de cachaça à luz da Teoria Institucional e da Visão Baseada em Recursos. REAd - Revista Eletrônica de Administração, Porto Alegre, v. 18, n. 1, p. 211-241, 2012.

SANTIAGO, R. Tributação injusta entre cachaça artesanal e industrial. Roberto Santiago Blog, 2007. Disponível em: <http://robertosantiago.blogspot.com. br/2007/01/cachaa-x-tributao.html>.

SCOTT, R. W. Institutions and Organizations: Ideas and Interests. 3a. ed. Thousand Oaks, CA: Sage, 2008.

SEBRAE - Serviço Brasileiro de Apoio às Pequenas e Médias Empresas. Diagnóstico da Cachaça de Minas Gerais. Belo Horizonte,2001,259 p.

. Cachaça artesanal. Série Estudos Mercadológicos, SEBRAE 2013 - Relatório Completo. Disponível em: $<$ goo.gl/TZ6edM>.

SILVA, F. R. Na embriaguês da cachaça: produção, imaginário e marketing (Minas Gerais 1982-2008). 2009. 111 f. Dissertação (Mestrado) - Universidade Federal de Uberlândia, Uberlândia, 2009.

e CRUBellate, J. M. Complexidade institucional: um estudo bibliométrico na publicação recente em teoria institucional. Revista Eletrônica de Ciência Administrativa-RECADM, v. 15, n. 2, p. 116-132, 2016.

SILVA, V. F. De cabeça de porco à bebida de negro: um estudo sobre a produção e o consumo da aguardente nas Minas Gerais no século XVIII. 2015. 247 f. Dissertação (Mestrado) - UFMG, Belo Horizonte. 2015.

SMETS, M., GREENWOOD, R. e LOUNSBURY, M. An institutional perspective on strategy as practice. In: GOLSORKHI, D. et al. (Eds.), The Cambridge handbook of strategy as practice. 2. ed. 283-300. Cambridge: Cambridge University Press, 2015.

SMETS, M. e JARZABKOWSKI, P. Reconstructing institutional complexity in practice: a relational model of institutional work and complexity. Human Relations, v. 66, n. 10, p. 1279-1309, 2013.

SMETS, M. et al. Reinsurance trading in Lloyd's of London: balancing conflicting-yet-complementary 
logics in practice. Academy of Management Journal, v. 58, n. 3, p. 932-970, 2015.

SORATTO, A. N., VARVAKIS, G. e HORII, J. A certificação agregando valor à cachaça do Brasil. Revista Ciência e Tecnologia de Alimentos, v. 27, n. 4, p. 681-687, out./dez. 2007.

SOUZA, M. A. F. e VALE, F. N. Considerações Estratégicas sobre a Indústria da Cachaça. In: Simpósio De Engenharia De Produção, 11., 2004, Bauru. Anais... Bauru: UNESP, 2004.

SOUZA V. L. O elo entre a produção, o consumo e a comunicação mercadológica da cachaça artesanal orgânica mineira. Publicatio UEPG: Ciências Sociais Aplicadas, Ponta Grossa, v. 20, n. 2, p. 169-77, jul./dez. 2012.

- e CUNHA, M. N. Aspectos sociais e publicitários na imagem da cachaça brasileira. Cadernos de Comunicação (UFSM), v. 17, p. 91-108, 2013.

THORNTON, P. H. e OCASIO, W. Institutional Logics. In: R. GREENWOOD et al. (Orgs.). The Sage Handbook of Organizational Institutionalism. Sage, 2008. p 99-129.

YU, K. Institutional Pluralism, Organizations, and Actors: A Review. Sociology Compass, v. 9, n. 6, p. 464476, 2015.

Todo o conteúdo deste periódico, exceto onde estiver identificado, está licenciado sob uma Licença Creative Commons (cc by 4.0). 